\title{
Congenital Prepubic Sinus with Remnant Tissue Mimics Corpus Spongiosum: A Rare Case
}

\author{
Suleyman Celebi ${ }^{1} \quad$ Özgür Kuzdan ${ }^{1} \quad$ Serdar Sander ${ }^{1}$ \\ ${ }^{1}$ Division of Pediatric Surgery, Kanuni Sultan Suleyman Training and \\ Research Hospital, Istanbul, Turkey \\ 2 Division of Pathology, Kanuni Sultan Suleyman Training and Research \\ Hospital, Istanbul, Turkey \\ ${ }^{3}$ Division of Pediatric Nephrology, Kanuni Sultan Suleyman Training \\ and Research Hospital, Istanbul, Turkey
}

Eur J Pediatr Surg Rep 2015;3:43-45.

\section{Nermin Gündüz ${ }^{2}$ Seyithan Özaydın ${ }^{1}$ Sevgi Yavuz ${ }^{3}$}

Address for correspondence Suleyman Celebi, Division of Pediatric Surgery, Kanuni Sultan Suleyman Training and Research Hospital, Istanbul, Turkey (e-mail: celebisuleyman@hotmail.com).

\begin{abstract}
Keywords

- congenital prepubic sinus

- corpus spongiosum

- dorsal urethral duplication

A congenital prepubic sinus is a tract that originates in the skin and overlays the base of the penis; however, its embryologic basis is still debated. We herein present a case involving a 3-year-old boy who was admitted for examination of overlying tissue located a few centimeters distal to the dorsal base of the penis. Examination revealed a tiny sinus in the prepubic area, and $3 \mathrm{~cm}$ of tissue was attached to the sinus. Pathologic examination showed that the tissue was lined with squamous epithelium and continued along the sinus tract, which was lined with urothelial epithelium. According to Stephens' classification, the sinus appeared to be a variant of type 2 dorsal urethral duplication, and the remnant tissue mimicked the corpus spongiosum of the penis.
\end{abstract}

\section{Introduction}

A small number of cases of congenital prepubic sinus (CPS) have been reported. ${ }^{1,2} \mathrm{CPS}$ is a rare congenital anomaly of the urinary tract. It is associated with discharge from an opening overlying the symphysis pubis, and affects both males and females. ${ }^{3}$ CPS may either be a complete or incomplete channel that runs parallel to the normal urethra from the prepubic glans or clitoral area and extends to the bladder, which may either join the urethra or end blindly. ${ }^{4}$ Dorsal urethral duplication and cloacal anomalies are assumed to be the causes of this condition. ${ }^{5}$ In most cases of CPS, a tiny hole is seen in the prepubic area. We herein report a case of CPS in which the tissue extending from the overlying skin mimicked the corpus spongiosum of the penis.

\section{Case Report}

A 3-year-old boy with weight of $12 \mathrm{~kg}$ was admitted for yellowish discharge from a tiny opening along the midline of the pubic-glans junction on the dorsal base of the penis. No other symptoms related to the genitourinary tract were noted. All clinical and laboratory findings were normal. Physical examination revealed a tiny sinus in the prepubic area and $3 \mathrm{~cm}$ of tissue, similar to the corpus spongiosum, attached to the sinus. Ultrasound (US) examination showed a sinus directed toward the bladder neck. Fistulography showed a noncommunicating fistulous tract coursing from the prepubic skin toward the bladder ( - Fig. 1).

During surgery, the overlying tissue located $3 \mathrm{~cm}$ from the base of the penis was excised and found to be continuous with the sinus tract. The sinus opening was probed and simple excision of the sinus tract was performed, revealing a tract approximately $4 \mathrm{~cm}$ long that extended to the retropubic space and ended in a fibrous tract. The postoperative course was uncomplicated, and the boy remains asymptomatic 1 year after the intervention. Histomorphological findings showed that the tissue was lined with squamous epithelium, and the accompanying urothelial residue was compatible with urothelial cysts and surrounded by focal smooth muscle layers. The entire sinus tract was lined with urothelial epithelium (-Fig. 2). received

August 10, 2014 accepted after revision

November 5, 2014

published online

December 12, 2014
DOI http://dx.doi.org/

10.1055/s-0034-1396787. ISSN 2194-7619.
@ 2015 Georg Thieme Verlag KG
Stuttgart · New York

License terms

(1) $\Theta \circledast$ 

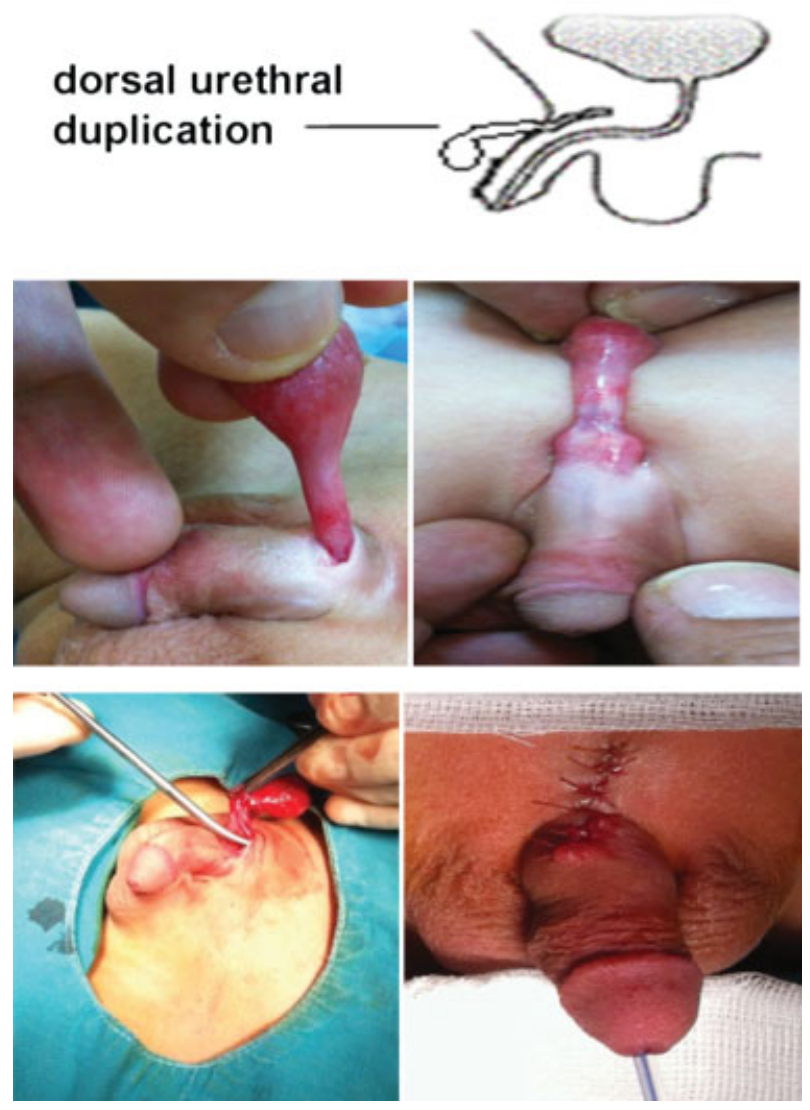

Fig. 1 Prepubic sinus with tissue mimicking corpus spongiosum.

\section{Discussion}

CPS is a rare condition, and few cases in children have been reported. The sinus usually passes from the base of the penis near the abdominal wall toward the anterior bladder without communicating with the urinary tract. ${ }^{6}$ The diagnosis is generally established by confirming the presence of the sinus tract using fistulography or the US. Magnetic resonance imaging may also be useful. The diagnosis in our case was confirmed with US, and fistulography revealed the precise anatomy of the sinus.

Variants of CPS have been reported, and because the anatomic features often differ, a consensus concerning the embryology and classification has not yet been established. Rozanski et $\mathrm{al}^{7}$ reported a case of CPS that represented a mild form of a midline closure defect. A second theory is that the defect does not allow for complete replacement of the ventral cloacal membrane by the lateral mesodermic folds, creating a fistulous tract. ${ }^{8}$ van der Putte $^{9}$ considered the basis for this condition to be congenital malformations of cloaca-derived orifices, such as hypospadias, epispadias, vesical and cloacal exstrophy, double urethra, and prepubic sinuses. Most reported cases of CPS have been characterized by a tiny opening in the prepubic area that was primarily surrounded by squamous epithelium. Campbell et $\mathrm{al}^{10}$ reported three cases of CPS in which the sinus tract was surrounded by stratified squamous epithelium or transitional epithelium with concentric bundles of collagen and smooth muscle fibers. The authors concluded that these sinuses may represent a variant of epispadiac duplication of the urethra. Huang et $\mathrm{al}^{1}$ performed an immunohistochemical study, and found that the epithelium lining was transitional proximally and squamous distally in five patients. They reinforced the theory that CPS is a variant form of dorsal urethral duplication. In our case, the squamous epithelium was surrounded by muscle and glands within the tissue, and urothelial epithelium was found within the sinus tract. The difference between the locations of the squamous epithelium and transitional epithelium may have been because of the fact that CPS reacts with ductal and glandular epithelia, including the urothelium. This finding might support the theory that dorsal urethral duplication is the etiology of this condition. Stephens ${ }^{11}$ stated that CPS might be caused by an inturned epithelial tube or remnant along the line of fusion of the infraumbilical abdominal walls, and classified this into three parts based on where the sinus begins. We believe that this case involved type 2 dorsal urethral duplication

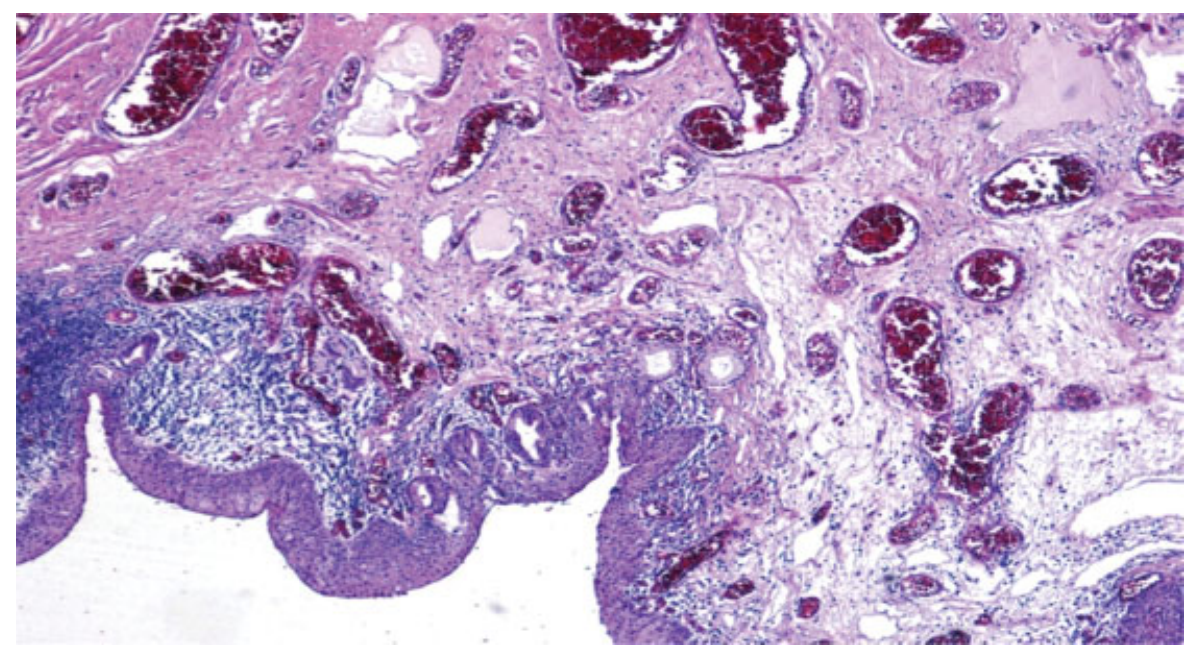

Fig. 2 Pathologic specimen of dorsal urethral duplication. 
according to Stephens' classification, which describes a sinus that simulates an accessory urethra and tract from the dorsum of the penis behind the symphysis pubis to the bladder wall. However, we found no previous studies indicating that the sinus continues with the urinary tract tissue mimicking the corpus spongiosum. It is possible that the sinus tract was hypertrophic because of the accumulation of discharge from the CPS.

In conclusion, the embryological explanation of the development of CPS is unclear. We postulate that all the previously reported cases may be manifestations of a wide spectrum of the same condition. However, according to most investigators, CPS may represent a variant of dorsal duplication of the urethra. To the best of our knowledge, this is the first case in which the CPS continued outward from the skin within the urinary tract. Complete excision is the most definitive form of treatment.

\section{References}

1 Huang C-C, Wu W-H, Chai C-Y, Wu TC, Chuang JH. Congenital prepubic sinus: a variant of dorsal urethral duplication suggested by immunohistochemical analysis. J Urol 2001;166(5):1876-1879
2 Kim HY, Shin OR, Jang ED, et al. Congenital prepubic sinus: a variant of urethral duplication. Korean J Urol 2007;48:881-884

3 Al-Wattar KM. Congenital prepubic sinus: an epispadiac variant of urethral duplication: case report and review of literature. J Pediatr Surg 2003;38(4):E10-E12

4 Balster S, Bettendorf O, Brinkmann OA, Hertle L. Congenital prepubic sinus: etiology and therapy [in German]. Aktuelle Urol 2003;34(7):484-487

5 Tsukamoto K, Yamataka A, Kuga T, Yanai T, Watanabe T, Miyano T. Congenital prepubic sinus: is it a residual cloacal membrane and umbilicophallic groove? Pediatr Surg Int 2004;20(1):47-50

6 Soares-Oliveira M, Juliá V, Aparicio LG, Morales L. Congenital prepubic sinus. J Pediatr Surg 2002;37(8):1225-1227

7 Rozanski TA, Kiesling VJ Jr, Tank ES. Congenital prepubic sinus. J Pediatr Surg 1990;25(12):1301

8 Nasir AA, Abdur-Rahman LO, Olaoye I, Oyinloye AO, Bamigbola KT, Adeniran JO. Congenital prepubic sinus: a variant of epispadiac dorsal urethral duplication. J Pediatr Urol 2013;9(1): e82-e85

9 van der Putte SCJ. Normal and abnormal development of the anorectum. J Pediatr Surg 1986;21(5):434-440

10 Campbell J, Beasley S, McMullin N, Hutson JM. Congenital prepubic sinus: possible variant of dorsal urethral duplication (Stephens type 2). J Urol 1987;137(3):505-506

11 Stephens FD. Abnormal Embryology-Cloacal Dysgenesis. Congenital Malformations of the Urinary Tract. New York, NY: Praeger Scientific.; 1983:22-23 